Quebradeiras de coco babaçu: (re)construindo identidades e protagonizando suas histórias na Microrregião do Médio Mearim, Estado do Maranhão

\author{
Anny da Silva Linhares
}

Na Amazônia, o advento de "novos" movimentos sociais objetivados em identidades coletivas têm demostrado transformações na organização política dos chamados povos e comunidades tradicionais. Após a experiência de luta pela não derrubada das palmeiras de babaçu e pelo direito a terra no final dos anos de 1980, mulheres agroextrativistas mobilizadas, passam a se posicionar na esfera política constituindo suas próprias organizações representativas, reivindicando direitos baseados no reconhecimento dos modos intrínsecos de "criar", de "fazer" e de "viver" deste grupo e acionando processualmente a identidade coletiva quebradeira de coco babaçu. Portanto, esta dissertação tem como objetivo analisar o processo de (re)construção da identidade coletiva quebradeira de coco babaçu, verificando sua associação com a constituição do patrimônio cultural, com ênfase em seu atual estágio. A pesquisa foi desenvolvida no Povoado de Ludovico, localizado na zona rural do Município de Lago do Junco, Estado do Maranhão, onde verificou-se que a identidade social e política das quebradeiras de coco está fundada na luta pela preservação dos babaçuais e nos saberes e fazeres herdados, que constituem seu patrimônio cultural construído na experiência vivida no passado e atualizado no tempo presente, contexto em que a experiência das crianças e jovens, filhos e filhas de quebradeiras de coco, também estão trazendo novos questionamentos sobre a ressignificação da identidade coletiva e dos patrimônios sob os quais a mesma se edifica.

\title{
Palavras- chave
}

quebradeiras de coco babaçu, identidade coletiva, patrimônio cultural.

Número de páginas: 289

\section{Banca examinadora}

Profa. Dra. Noemi Sakiara Miyasaka Porro (Orientadora- UFPA;

Profa. Dra. Sheilla Borges Dourado (PNCSA);

Profa. Dra. Rosa Elisabeth Acevedo Marin (UFPA)

Data e local de defesa da Dissertação:

29/03/2016 às 14h:00min, no Auditório NCADR. 


\title{
"Sindicato é pra quem entende": (Des)igualdade de genêro no sindicalismo dos empregados rurais de Moju
}

\section{Suellen Suzy de Souza Costa}

\begin{abstract}
A maior inserção da mulher rural nos sindicatos e nos demais movimentos e organizações se dá principalmente a partir início da década de 1980. Mesmo assim, a posição de liderança no movimento sindical ainda é restrita para as mulheres. Neste trabalho analisei a atuação de lideranças femininas assalariadas à dendeicultura na diretoria do Sindicato dos Empregados Rurais de Moju - SERMTAB. A pesquisa foi realizada com abordagem predominantemente qualitativa, por meio de um estudo de caso no município de Moju, Pará. Foram realizadas entrevistas não-diretivas e semiestruturadas com os membros da diretoria do sindicato composta por 09 diretores, dos quais, 3 são mulheres. As principais conclusões demonstram que o SERMTAB é a maior entidade de representação dos empregados rurais de Moju. A diretoria advém da agricultura familiar, é diversa com jovens, mulheres e homens mais velhos, porém mantém os espaços de decisão restritos às figuras masculinas. Com a sua atuação comprometida e relação de poder hierarquizada, colocam as mulheres em uma condição subalterna e de domínio masculino. Contudo, o rompimento das relações de poder ocorre de maneira sutil, ao aceitarem participar e fazerem o enfretamento familiar, entrarem em embates com outros trabalhadores e encararem os preconceitos por serem sindicalistas. Ainda assim, sua ausência formal na direção dificulta o surgimento de sua identidade enquanto trabalhadora rural assalariada e sindicalista.
\end{abstract}

\section{Palavras- chave}

liderança, sindicalismo rural, relação de poder, mulheres, relação de gênero.

Número de páginas: 108

\section{Banca examinadora}

Profa. Dra. Dalva Maria Mota (Orientadora- EMBRAPA);

Profa. Dra. Leonilde Servolo de Medeiros (UFRRJ);

Profa. Dra. Maria Luzia Álvares (UFPA).

Data e local de defesa da Dissertação:

31/03/2016 às 09h:00min, no Auditório NCADR 


\title{
A várzea está para peixe: Viabilidade, socioeconômica da piscicultura praticada na bacia do Aricurá, Cametá, Pará
}

\author{
Walmiro Amador da Silva Junior
}

A partir da década de 1980, em resposta à redução do estoque pesqueiro os agricultores do baixo Tocantins passaram a criar peixe em cativeiro, através de viveiro escavado em várzea os quais os agricultores chamam de tanque. Por se tratar de uma atividade introduzida recentemente ao sistema de produção, objetivou-se através deste trabalho investigar se a introdução provocou mudanças nos aspectos socioeconômico dos estabelecimentos rurais. A pesquisa foi realizada no distrito Sede do município de Cametá, mais precisamente na bacia do rio Aricurá que tem os igarapés Ajó e Merajuba como seus tributários. A área de estudo se destaca pela diversidade quanto ao ecossistema, com presença de várzea, e de terra firme. O estudo envolveu 18 estabelecimentos e foi realizado em 3 etapas. Na primeira foi elaborada uma tipologia do sistema de produção. Na segunda, já com a formação de dois tipos, um formado por estabelecimentos que apresentam área de várzea e de terra firme, e outro por estabelecimentos que apresentam somente área de várzea, foram selecionados 4 estabelecimento para representar cada tipo. Em todos os estabelecimentos selecionados foram levantados o itinerário técnico da piscicultura, efetuada uma análise de paisagem, entrevistas sobre o histórico e elaborado um croqui. Na terceira e ultima etapa, para analisar em profundidade as possíveis mudanças na relação social do trabalho, foi realizado um estudo de caso de uma unidade de produção. Em estabelecimento familiar, em virtude do pequeno porte, cerca 54 ha, a produção ocorre de maneira consorciada. Apesar da grande diversidade, as atividades são organizadas para diminuir a competição por espaço produtivo entre elas.Por isso, apesar da introdução da piscicultura tornar o sistema ainda mais complexo, não provocou o rearranjo espacial das áreas de produção, seja em estabelecimento com disponibilidade só de várzea, como naqueles com várzea mais terra firme. Por outro lado houve redução na intensidade e no recrutamento de força de trabalho aplicada à extração aquática (pesca e captura do camarão), essa que antes era praticada quase todas as noites, passou a ser realizada cerca 3 dias por semana. Outra coisa importante é que quando a criação passou a ser planejada para atender o mercado local, o peixe oriundo da piscicultura transformou-se em ingresso ao mercado e gerador de renda com efeito significativo na circulação do capital, assumindo o papel, que antes era somente dos produtos aquáticos. A piscicultura praticada em várzea por agricultores familiares tem garantido a reprodução socioeconômica do grupo familiar, sem que haja competição pela mão de obra e pelo espaço e pode ser desenvolvida sem impacto ambiental.

\section{Palavras- chave}

relação social do trabalho, estabelecimento familiar, piscicultura familiar, criação de peixe em várzea

Número de páginas: 95

\section{Banca examinadora}

Prof. Dr. Paulo Fernando da Silva Martins (Orientador- UFPA);

Prof. Dr. Luís Otávio do Canto Lopes (UFPA);

Prof. Dr. Rosildo Santos Paiva (UFPA).

Data e local de defesa da Dissertação:

31/05/2016 às 14h:00min, no Auditório NCADR. 
Segurança alimentar em projetos de assentamento de reforma agrária com ênfase ambiental: estudo de caso no Projeto de Desenvolvimento Sustentável Virola Jatobá, Transamazônica, Estado do Pará

\author{
Cezário Ferreira dos Santos Júnior
}

A presente pesquisa busca compreender as questões alimentares e socioambientais através da análise das práticas agrícolas e das experiências florestais dos agricultores, visto que a produção de alimentos (para consumo e renda) para os grupos sociais tradicionais na Amazônia é um importante elemento na garantia da segurança alimentar, pois utilizam os recursos florestais e agrícolas na manutenção da unidade familiar. Este estudo de caso toma como empiria o Projeto de Desenvolvimento Sustentável (PDS) Virola Jatobá, situado na região da Transamazônica, município de Anapu/PA. Esta modalidade de assentamento traz o debate emblemático sobre a articulação entre questões ambientais, agrícolas e florestais, com a possibilidade da exploração madeireira legal através do manejo florestal comunitário. Utilizou-se o método quanti-qualitativo, realizando-se o levantamento de dados através de observações direta e participante, entrevistas e aplicação de questionário socioeconômico. Por meio dos quais compreendeu-se as transformações sócio produtivas ocorridas ao longo da trajetória de vida dos assentados. Os resultados da pesquisa apontam para mudanças das práticas sobre a segurança alimentar dos assentados em função das questões ambientais sobre os sistemas tradicionais de produção.

\title{
Palavras- chave
}

Socioambiental. Unidade familiar. Transamazônica. Segurança alimentar.

Número de páginas: 152

\section{Banca examinadora}

Profa. Dra. Noemi Sakiara Miyasaka Porro (Orientadora- UFPA);

Prof. Dr. Roberto Porro (EMBRAPA);

Prof. Dr. Paulo Fernando da Silva Martins (UFPA).

Data e local de defesa da Dissertação:

31/03/2016 às 10h:00min, no Auditório NCADR. 


\section{Manejo de população de açaizeiro (Euterpe olecarea Mart.) em parcelas de produção de frutos em área de várzea}

\section{Amália Gabriela Rocha Aguiar}

O manejo da touceira do açaí é feito com o objetivo de aumentar a produção de frutos e se dá pela eliminação dos estipes pouco produtivos ou estipe excedentes, bem como outras espécies do seu entorno, com a finalidade de reduzir a concorrência ecológica por água, luz e nutrientes. $\mathrm{O}$ objetivo da pesquisa foi de contribuir com o manejo sustentável do açaizeiro a partir da relação entre as diferentes formas de manejo e a produção de frutos. O estudo foi realizado em três parcelas de manejo adotadas em uma área de um produtor selecionado dentre os 6 produtores visitados na comunidade de Manoel Raimundo, distrito de Janua Coeli no município de Cametá, se tratando, portanto, de um estabelecimento em meio real camponês. A partir de uma abordagem qualitativa e quantitativa, bem como de procedimentos metodológicos como: observação e análise da paisagem, entrevistas, formulários e amostragem semi-aleatória foi possível identificar e selecionar as parcelas de manejo através dos diferentes modos de manejo em relação às práticas de controle da densidade das plantas decorrente do desbaste de estipe nas touceiras, da eliminação ou raleamento da vegetação acompanhante. Considerando o histórico de manejo das parcelas elas foram tomadas como tratamento e denominadas de: Parcela 1 (Manejo do agricultor) Parcela 2 (Manejo de orientação técnica), e Parcela 3 (Extrativismo). No interior de cada uma delas foram demarcados com piquetes três subparcelas com dimensões de $6 \mathrm{~m}$ x $12 \mathrm{~m}$ cada que corresponderam as repetições do experimento. Foram efetuadas amostragens para caracterizar morfologicamente a população vegetal através dos indicadores: quantidade de touceiras por área, quantidade de estipe por touceira, quantidade de cachos por estipe, quantidade de ráquilas por cacho, quantidade de frutos por ráquilas e peso dos frutos. Os dados levantados nos locais se referem às plantas acompanhantes, as plantas de açaí, a intensidade de luz no ambiente, ao $\mathrm{pH}$ e a umidade do solo. Os resultados mostraram alta variabilidade dos indicadores estudados nas parcelas e nas repetições. Além disso, identificaram-se três formas de corte de touceiras sendo elas classificadas como leve, forte e sem corte. A pesquisa aponta para o manejo como o principal fator do rendimento dos frutos.

\section{Palavras- chave}

manejo de açaizeiros, ecossistema de várzea, agricultura familiar, parcelas de produção.

Número de páginas: 95

\section{Banca examinadora}

Prof. Dr. Paulo Fernando da Silva Martins (orientador-UFPA);

Prof. Dr. João Tomé de Farias Neto (EMBRAPA);

Prof. Dr. Francinei Bentes Tavares (UFPA).

Data e local de defesa da Dissertação:

31/05/2016 às 14h:00min, no Auditório NCADR. 


\section{Labor e prazer: a prática e o sentido dos mutirões na comunidade Monte Sião, São Domingos do Capim - PA}

\section{Josiele Pantoja de Andrade}

Objetivamos nesse trabalho compreender as práticas e o sentido do mutirão e como os mesmos contribuem para o estabelecimento das relações de reciprocidade camponesa, a partir de uma análise do trabalho, em especial em mutirões, como parte integrante da vida camponesa, entendido como um espaço de reprodução da vida cotidiana. Esse estudo foi realizado na comunidade Monte Sião, Nordeste Paraense. Para a realização da pesquisa, optamos pela abordagem metodológica qualitativa, entretanto, métodos quantitativos também foram utilizados como uma forma de auxiliar a interpretação da realidade social. Como estratégia metodológica, utilizamos o estudo de caso, realizado com 45 famílias, nos valendo da observação participante, entrevistas e questionários, os quais permitiram compreender a história de formação da comunidade, a instalação da igreja Assembleia de Deus, a organização da APEPA, os festejos, a divisão social do trabalho na unidade de produção familiar, os espaços de sociabilidade e, sobretudo, compreender a organização dos distintos mutirões e as relações de reciprocidade que se estabelecem entre camponeses e camponeses e divindades, além apreendermos a noção de mutirão que os camponeses detêm. $\mathrm{O}$ estudo aponta a reciprocidade na essência camponesa. O mutirão até o século XX era realizado para auxílio em trabalhos agrícolas, em casos de doença, especialmente nos trabalhos das roças de mandioca. Havia duas formas de realizar o trabalho dos roçados: o mutirão e o trabalho de companhia. O primeiro, uma forma de ajuda mútua não formalizada, porém entendida como um contrato moral; o segundo entendido como uma forma institucionalizada, composto por um grupo fixo de camponeses, com registro hierárquico dos cargos ocupados e das atividades a serem executadas. Com as transformações socioeconômicas, a entrada da comercialização do açaí e a diminuição dos recursos naturais, as roças deixaram de ser a principal atividade econômica dos camponeses e, como consequência, o trabalho de companhia deixava de existir no trabalho dos roçados, sendo ressignificado e ganhando força em outras atividades, como na instituição religiosa, onde os camponeses se reúnem em mutirões movidos por um sentimento de fé e amizade para realizar determinados trabalhos, como construções, festejos, artesanatos e campanhas para captar recursos financeiros para doar a Deus, uma relação de reciprocidade entre os homens e Deus. A Associação, durante um período, também acionou os mutirões para o manejo dos açaizais e confecção de artesanatos. E, por último, o mutirão organizado pelos camponeses para ter acesso à energia elétrica. Esses mutirões ultrapassam a ideia utilitarista, são entendidos como um espaço pedagógico de aprendizagem coletiva. E, mais ainda, como uma forma de ação política, além de representar a união dos camponeses e a luta por acesso a serviços públicos historicamente negados. Eles não existem separados do restante da vida. Durante o trabalho as pessoas conversam da vida, fofocam, dão risos, fazem brincadeiras e até podem ocorrer desentendimentos. Assim, concluímos que os mutirões, em Monte Sião, continuam vivos na essência camponesa, sendo ressignificados e acionados de acordo com as necessidades econômicas, sociais, políticas, religiosas e culturais da comunidade. 


\section{Palavras- chave}

reciprocidade; ressignificação dos mutirões; igreja; reprodução do conhecimento.

Número de páginas: 138

\section{Banca examinadora}

Prof. Dr. Osvaldo Ryohei Kato (Orientador- UFPA);

Profa. Dra. Ruth Helena Cristo Almeida (Co-orientadora- UFRA);

Prof. Dr. Andrey Faro de Lima (UFPA);

Profa. Dra. Sônia Maria S. B. Magalhães Santos(UFPA).

Data e local de defesa da Dissertação:

31/08/2016 às 10h:00min, no Auditório NCADR. 


\title{
Regularização Ambiental Rural: (des)encontros entre o instituído e o executado no Projeto de Assentamento Águia - Paragominas/Ulianópolis (PA)
}

\author{
Maria da Conceição Silva Rosa
}

Com a publicação da Lei $\mathrm{n}^{\mathrm{o}}$ 12.727/2012 que instituiu o novo código florestal, o processo de regularização ambiental se tornou obrigatório para todos os imóveis rurais, e definiu o cadastro ambiental rural (CAR) como um de seus principais instrumentos e a adesão a este instrumento como primeira etapa do referido processo. Considerando a obrigatoriedade deste instrumento, sua inexpressividade nas áreas de assentamento, bem como os passivos ambientais nelas identificados, o presente trabalho tem como objetivo geral analisar como a regularização ambiental está se processando nos assentamentos de reforma agrária, em particular na Comunidade Rio Bonito localizada no Projeto de Assentamento Águia, em Paragominas/Ulianópolis-PA, partindo da compreensão e vivência que os próprios assentados possuem sobre tal processo. A pesquisa se desenvolveu em três etapas: a pesquisa bibliográfica, documental e a pesquisa de campo. O estudo de caso foi realizado na Comunidade Rio Bonito, uma das quatro agrovilas do projeto de assentamento Águia, com 35 famílias, do total de 68 existentes no projeto de assentamento. Utilizando-se de observação participante, entrevistas livres e semi-estruturadas buscou-se identificar as noções que assentados possuíam sobre a regularização ambiental rural e seus instrumentos, e as transformações que ocorreram na dinâmica produtiva do assentamento e na vida dos assentados com sua implantação. A observação desta realidade, em particular, nos permitiu afirmar que a implementação deste processo não refletiu em alterações significativas na dinâmica produtiva, ambiental e social do assentamento. As mudanças observadas na realidade deste PA como a redução do desmatamento, a eliminação do uso do fogo nas atividades produtivas e a adoção de posturas mais conscientes em relação à conservação das Áreas de Preservação Permanente (APP) e dos fragmentos de floresta ainda existentes, não foram decorrentes do processo de regularização ambiental e da implantação do CAR, e de acordo com os assentados os benefícios deste instrumento resumiu-se à facilitação de liberação de financiamentos bancários destinados aos projetos da agricultura familiar.

\section{Palavras- chave}

Regularização ambiental rural. Assentamentos rurais. Agricultura familiar. Cadastro ambiental rural.

Número de páginas: 141

\section{Banca examinadora}

Prof. Dr. Osvaldo Ryohei Kato (Orientador- UFPA);

Prof. Dr. José Heder Benatti (UFPA);

Prof. Dr. Gutemberg Armando Diniz Guerra (UFPA).

Data e local de defesa da Dissertação:

09/15/2016 às 15h:00min, no Auditório NCADR. 


\section{Do dendê eu tenho medo até dos espinhos: Resistência cotidiana à agroindústria do dendê pelos camponeses de Maçaranduba- Tomé Açu, no nordeste paraense}

\section{Noemi Diniz Sacramento}

Construí esta dissertação com o objetivo de analisar as formas cotidianas de resistência à integração à agroindústria do dendê, a partir dos camponeses da colônia Maçaranduba, localizada no município de Tomé-Açu, região nordeste do estado do Pará. As formas cotidianas de resistência não são assuntos costumeiros dentro das pesquisas sobre resistência por estarem subscritas no cotidiano das sociedades camponesas que nem sempre permitem aos pesquisadores tomá-las como objeto de análise. Maçaranduba está geograficamente inserida na zona de expansão do monocultivo de dendê, em que a integração é um mecanismo utilizado pelas agroindústrias para a expansão das áreas cultivadas com dendezeiro, subsidiada pela criação do Programa Nacional de Produção e Uso de Biodiesel (PNPB) e do Programa de Produção Sustentável da Palma de Óleo (PSOP). Destarte assumi que os sujeitos não são estáticos, mas que desenvolvem justificativas, opiniões e atribuem sentido às suas escolhas baseados nos projetos que a família possui e no "medo" que a integração possa reduzir a autonomia a que estão habituados possuir. Utilizei como base teórica as reflexões de James Scott, autor que considera o cotidiano o lugar onde a resistência camponesa se torna plausível e concreta. A metodologia partiu de um estudo de caso, que permitiu compreender como os sujeitos de Maçaranduba empreenderam a resistência à integração, para conceber os dados foram aplicados trinta questionários cuja organização das perguntas se centrou sobre o conhecimento das famílias sobre o programa e de seus posicionamentos acerca da integração, além de entrevistas a informantes chaves para conhecimento da história local e a agentes públicos envolvidos no debate. Com a pesquisa constatei que as famílias elaboram suas justificativas para a resistência a partir de suas experiências cotidianas, sempre pensando em projetos produtivos que garantam a permanência da família no estabelecimento agrícola, rejeitando projetos que assumam riscos para a manutenção das gerações futuras. Observei ainda que as famílias adquirem conhecimento sobre a integração a partir de uma rede invisível de informação que tecem entre os sujeitos que fazem parte dos seus cotidianos, entre eles estão as famílias residentes em localidades próximas e que aderiram ao projeto. Apesar da resistência à integração, os camponeses de Maçaranduba sentem os reflexos da expansão dos cultivos de dendezeiro, através da aplicação de agrotóxicos nos cultivos próximos e na modificação da paisagem a que estavam habituados.

\section{Palavras- chave}

resistência cotidiana; camponeses; dendezeiro.

Número de páginas: 100

\section{Banca examinadora}

Prof. Dr. Gutemberg Armando Diniz Guerra (UFPA);

Profa. Dra. Leonilde Servolo de Medeiros (UFRRJ);

Prof. Dr. William Santos de Assis (UFPA).

Data e local de defesa da Dissertação:

25/15/2016 às 14h:30min, no Auditório NCADR 
